\title{
PLANO DE AÇÃO DA ACESSIBILIDADE FÍSICA PARA CAMPUS UNIVERSITÁRIO NO CEARÁ
}

\author{
SOBREIRA, Vládia Barbosa \\ Faculdade Católica Rainha do Sertão, Mestre \\ e-mail:vladiashanti2017@gmail.com
}

\begin{abstract}
RESUMO
O Plano de Ação da Acessibilidade Física tem o intuito de orientar as Instituições Particulares de Ensino Universitário na adequação de seus ambientes construídos á acessibilidade física. Ações preliminares definem ás necessidades e expectativas das pessoas com deficiência física. Decorrem as diretrizes para intervenção no ambiente existente, baseadas na ABNT NBR-9050. No Plano de Ação, o Diagnóstico inicia-se com o levantamento dos elementos acessíveis existentes no Campus, segue-se a definição de critérios para as reformas e adaptações e os projetos de arquitetura e urbanismo. As áreas de atuação serão implementadas no curto, médio e longo prazo.
\end{abstract}

Palavras chave: Acessibilidade Física; Plano de Ação para Acessibilidade; Ambiente Acessível.

\begin{abstract}
The Plan of Action of Physical Accessibility intends to orient the Private Universities to adequate their physical environment to physical accessibility. Preliminary actions define the necessity and expectations of people with physical impairment. There are the directives for the intervention in the existing environment, based on ABNT NBR-9050. In the Plan of Action, the diagnosis begin with the catalogue of existing accessible elements in the campus, then follows the definition of criteria for remodeling and adaptation, and the architectural and urbanistic projects. The areas of action are implemented in the short, medium and long run. $\quad$ (10 pts, itálico).
\end{abstract}

Keywords: Physical Accessibility; Plan of Action to Accessibility; Accessible Environment.

\section{PLANO DE AÇÃO DA ACESSIBILIDADE FÍSICA PARA CAMPUS UNIVERSITÁRIO NO CEARÁ.}

\section{Introdução}

A Faculdade Católica Rainha do Sertão é uma Instituição inserida na região do sertão central do Ceará, na cidade do Quixadá, que iniciou suas atividades em 2004. Desde então vem investindo na ampliação e modernização de sua infraestrutura, assim como novas e modernas tecnologias educacionais. Compreendeu que era de muita importância desenvolver projetos que objetivassem implementar uma política de promoção da Acessibilidade no Campus em sua completude, orientado para um sistema de ensino inclusivo, inclusive servindo como modelo de referência para a cidade.

Desta forma, compreendeu sobremaneira que o significado da vida no processo do cuidado inclui não somente atribuições técnicas do profissional, mas capacidade de perceber e compreender o ser humano, como ele está em seu mundo, como desenvolve sua identidade e constrói a sua própria história da vida. (Betinelli, 2003) 


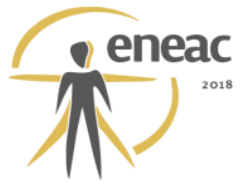

Voltado para esta visão específica, o Plano de Ação da Acessibilidade Física no Campus da FCRS, implantou uma política de promoção da acessibilidade, por meio da adequação arquitetônica, urbanística e da sinalização do seu espaço construído. Visou suprimir as barreiras arquitetônicas e urbanísticas e adequou sinalização apropriada ás pessoas com deficiência, almejando sua maior satisfação no ambiente de ensino e pesquisa de sua Faculdade.

A importância deste Plano consistiu na organização das ações para o projeto de arquitetura e de engenharia e na garantia do resultado de oferecer uma faculdade acessível.

\section{Metodologia}

A metodologia do trabalho se equipara a metodologia do Processo do Projeto Arquitetônico; Foram definidas a etapa de levantamento das necessidades para o projeto, em segundo momento foram estabelecidos os critérios de avaliação das necessidades e no terceiro momento, a projetação.

Especificamente, portanto, foram definidas 3 Fases específicas:

Fase 1- Anamnese. Que consistiu no levantamento das barreiras arquitetônicas e urbanísticas existentes no Campus, em diversos ambientes prioritários. As necessidades geradoras para o projeto aconteceram através de imagens captadas de ambientes e levantamento dos elementos acessíveis existentes no Campus, que justificassem intervenções necessárias para atender ás determinações da norma NBR-9050

Fase 2 - Diagnóstico. Nesta etapa, todas as medidas necessárias para a elaboração dos projetos arquitetônicos, urbanísticos e de sinalização foram agrupados em ações. As ações agruparam projetos semelhantes.

São dez tipologias de ação, necessárias para a execução dos projetos de acessibilidade no Campus. Idealizadas para a organização de prioridades de projeto e execução.

Estão assim definidas:

\section{BARREIRAS ARQUITETÔNICAS}

AÇÃO 1: Acessibilidade nas Circulações

AÇÃO 2: Adequação de Ambientes Internos

AÇÃO 3: Acessibilidade em Ambientes para Eventos Públicos

AÇÃO 4: Reforma de Mobiliário

AÇÃO 5: Projeto para Mobiliário de Sala de Aula

BARREIRAS URBANÍSTICAS

AÇÃO 6: Circulação Externa; Organização dos acessos e caminhos,

definições de estacionamentos acessíveis

AÇÃO 7: Elaboração de Mobiliário Urbano

AÇÃO 8: Praças Acessíveis

SINALIZAÇÃO

AÇÃO 9: Implantação da sinalização Tátil

AÇÃO 10: Sinalização para Obstáculos Suspensos.

Fase 3 - Plano de Ação para Execução de Projetos de Arquitetura e Obras de Engenharia. Realizados projetos arquitetônicos e urbanísticos e de Sinalização para a 


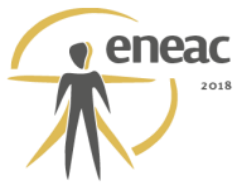

Acessibilidade Física no Campus da Faculdade Católica do Quixadá, atendendo a Lei no. $10.098 / 2000$ em defesa do direito de ir e vir de cada cidadão brasileiro.

\section{Resultados e Discussão}

$\mathrm{Na}$ elaboração da Anamnese, os ambientes que exigiam maior adequação ás normas existentes foram o Centro de Atendimento ao Aluno, onde a altura das bancadas estava a nível superior do recomendado, a Biblioteca, que apresentava inclinações de piso em soleiras e inexistência de banheiros públicos; Auditório e Videoteca, que apresentavam dificuldade no acesso da pessoa deficiente em cadeiras de rodas, Lanchonetes, com balcões demasiados altos para pessoas em cadeiras de rodas também, ausência de Banheiros Públicos para alunos, professores e funcionários, Setor de Fisioterapia, com inexistência de vestiários apropriados.

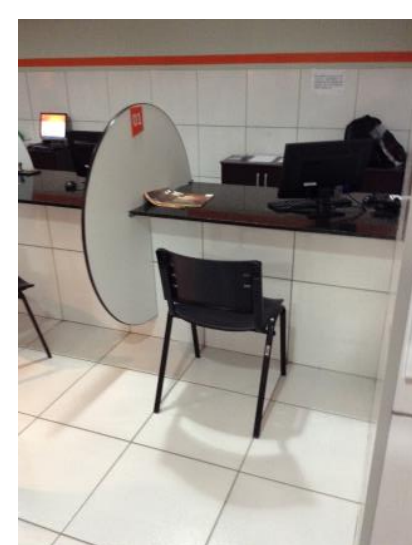

Centro de Atendimento Bancadas Altas

Fotos da autora

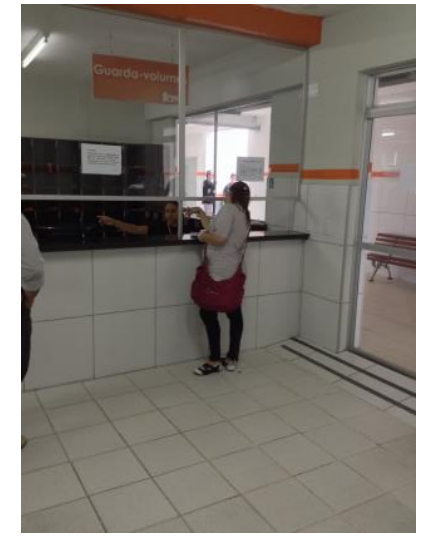

Biblioteca Inclinação de piso

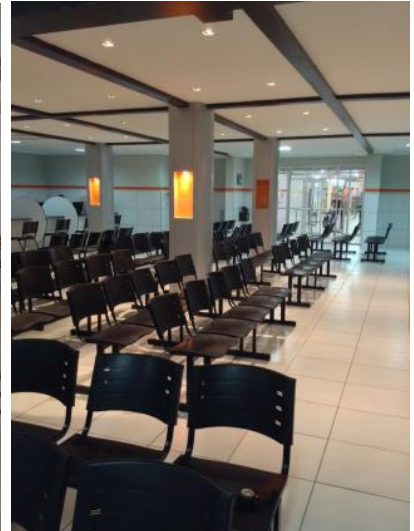

Banheiro inadaptado

Recepção Inexistência de espaços apropriados aos PcDs

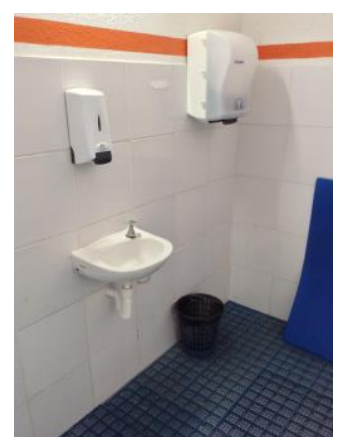

Havia inexistência de luz em alguns ambientes mais internos. Como cita esta Norma: Luz é essencial para a percepção da cor. Pessoas com deficiência visual podem não ser capazes identificar as cores, mas podem perceber tons claros e escuro, uma vez que esta característica é intrínseca das superfícies coloridas. O contraste visual entre superfícies adjacentes facilita a percepção e a legibilidade da informação desejada pelas pessoas com deficiência visual. (ABNT NBR 9050, 2015)

No Levantamento das Barreiras Urbanísticas, acontecia insuficiência de número de vagas de estacionamento para pessoas PcDs, algumas calçadas possuíam larguras insuficientes para a circulação de pessoas em cadeiras de rodas e as rampas externas não indicavam inclinações apropriadas. Eram estas as principais questões.

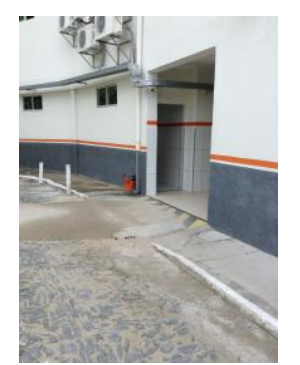

Calçadas com larguras insuficientes

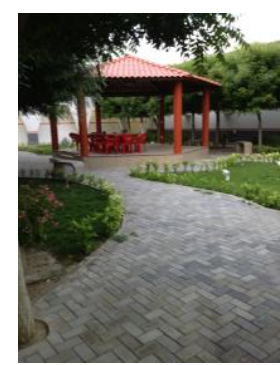

Degraus impedem o acesso de cadeirantes

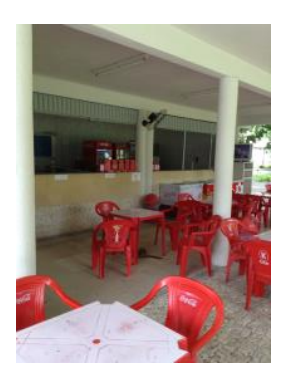

Lanchonetes com balcão alto

Fotos da autora 


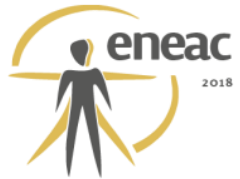

Durante a fase de elaboração de projetos, muitas unidades de banheiros acessíveis foram inseridas para o uso de pessoas com deficiência em blocos diferenciados.

Balcões de atendimento foram modificados e rebaixados, implementamos o caminho acessível desde a vaga de estacionamento do cadeirante em sua entrada principal e acesso secundário favorável foram sugeridos.

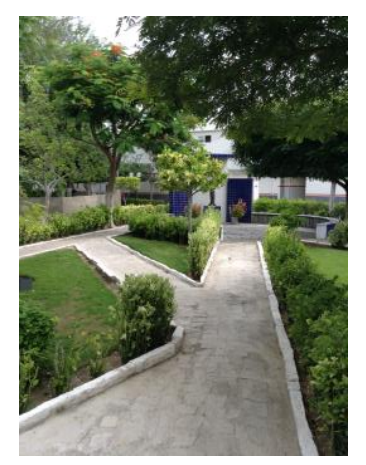

Caminhos irregulares e inacessíveis em áreas externas.

Dificuldade de acesso por PcDs

Foto da autora

$\mathrm{Na}$ etapa de projetação, o elemento mais redundante foram as reformas nos banheiros existentes, e a aplicação do piso tátil nos estacionamentos, com reformulação das rampas de acesso nas inclinações necessárias.

Condições de uso anterior da edificação, quando esta se destinava ao uso religioso, haviam tornado enclausurados os banheiros. Existiam cabines fechadas internas para sanitários, sem muita claridade e ventilação. Houve necessidade de maiores aberturas para ventilação e amplitude de espaços. Foram os elementos mais trabalhados na reforma.

Também o piso tátil desde o acesso principal foi concretizado e o caminho acessível possibilitou a chegada nas recepções existentes, das pessoas com deficiência com maior segurança e agilidade.

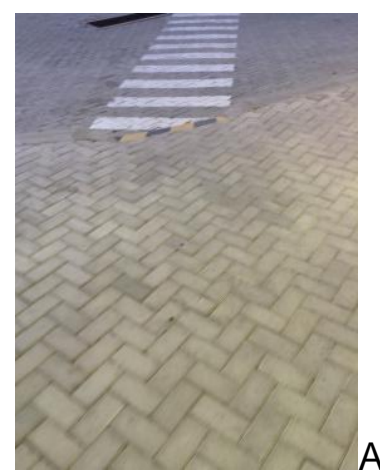

Acesso de faixa de travessia sem sinalização, que se destina á entrada lateral da Central de Atendimento

\section{Foto da Autora}




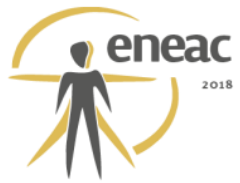

As áreas públicas, como Auditórios e Biblioteca tiveram inseridos banheiros acessíveis e balções com atendimento apropriado, revisados que foram sua ergonomia.

No geral, a Ergonomia dos mobiliários foram reajustados, a carteira acessível ergonomicamente projetada foi instituída e as circulações; os espaços de fluxos, foram enlarguecidos e ampliados.

A Faculdade se abriu para uma nova realidade.

\section{Conclusão}

O que move a humanização do espaço? O que move a acessibilidade? Por que nos tornamos sensíveis? O que nos conduz?

As normas com suas fiscalizações, sua obrigatoriedade, são os maiores pesos? o desejo de ir mais além?

Neste processo de convivência com a Acessibilidade, entretanto, o quê mais se percebe no resultado é a vantagem da autonomia . das pessoas com deficiência, sua gratidão com o espaço, sua realização como pessoa, seu bem estar inafiançável.

No processo do projeto arquitetônico aprendemos que a satisfação do usuário como pessoa é o inicio para a elaboração dos espaços, quer internos, quer externos. Neste processo de adequação da Faculdade o usuário era cada aluno presente. O espaço se adequava para todos independente de serem pessoas cadeirantes. A faculdade não dispunha de nenhuma situação desta e se preparava para recebê-los. Pessoas com mobilidade reduzidas, gestantes, idosos, circulavam, vivenciavam, mas alunos cadeirantes não estavam inscritos.

Com este olhar para o futuro foi que começamos a reorganizar o presente.

Parabéns aos gestores, que se faziam sérios.

Podemos depois de três anos passados avaliar o mérito desta ação que se fazia presente. Logo no final de 2015, a norma foi revisada e mais e mais detalhes foram agregados e fortalecidos. Entendemos, que seja um caminho grandioso de independência tornar a arquitetura e a cidade acessíveis.

\section{REFERÊNCIAS}

ABNT NBR 9050: 2015 Acessibilidade a edificações, mobiliário, espaços e equipamentos urbanos. Brasil, 2015.

BETINELLI. Luiz Antonio. Et al. Humanização do cuidado no ambiente hospitalar. O Mundo da Saúde - São Paulo, ano 27 v.27 n.2 abr./jun. 2003

Decreto Federal no. 6949/09, Convenção sobre os direitos das Pessoas com Deficiência.

Lei Federal no. 13146/15, Lei Brasileira de Inclusão de Pessoa com Deficiência (Estatuto da Pessoa com Deficiência) 